\title{
Growth and yield response of mungbean (Vigna radiata L. Wilczek) genotypes to wet puddling, flooding and saturated soil culture
}

\author{
M. Rafiqul Islam ${ }^{1, ~ *, ~ N u r u n n a h e r ~ A k t e r ~}{ }^{1}$, S. M. Shahriar Parvej ${ }^{2}$, K. M. Shamsul Haque ${ }^{1}$ \\ ${ }^{1}$ Department of Agronomy, Bangabandhu Sheikh Mujibur Rahman Agricultural University, Gazipur-1706, Bangladesh \\ ${ }^{2}$ Agriculture Information Service, New Truck Road, Chandpur-3600, Bangladesh
}

Email address:

rafiarib@yahoo.com (M. R. Islam)

\section{To cite this article:}

M. Rafiqul Islam, Nurunnaher Akter, S. M. Shahriar Parvej, K. M. Shamsul Haque. Growth and Yield Response of Mungbean (Vigna radiata L. Wilczek) Genotypes to Wet Puddling, Flooding and Saturated Soil Culture. Journal of Plant Sciences. Vol. 2, No. 6, 2014 , pp. 311-316. doi: $10.11648 /$ j.jps.20140206.18

\begin{abstract}
Anoxia and hypoxia, caused by excessive rainfall and inadequate drainage are the most common environmental stresses in upland crops after wetland rice in many regions of Asia. Such stresses and/or puddling of soil in rice culture often reduce the growth and yield of post-rice upland crops. This study examined the growth and yield responses of three mungbean genotypes viz. VC3950-88, VC6173A and BARI Mung-5 to three different environmental stresses viz. wet puddling, soil flooding and saturated soil culture. Wet puddling significantly reduced the field emergence and vigor index of seedlings. Height of plants was also adversely affected due to the stresses, although recovery was comparatively better in flooded situation. Irrespective of growing conditions, leaf chlorophyll index reduced significantly and recovered almost completely. The extraordinary responses of plants to all the stresses were the damaging of roots and/or impairing of root and shoot growth. The subsequent recovery of root and shoot growth significantly varied depending on the types of stresses. The development of numerous adventitious roots and the production of greater amount of root nodules were the most important recovery mechanisms of plants to withstand flooding situation and saturated soil culture, respectively. As a result, seed production was less affected under these two conditions. In contrast, wet puddling situation performed the worst, showing depressed plant growth throughout the growing period and thus seed production was affected the most. Among the genotypes, VC6173A was best adapted under the three stresses, giving the highest seed yield by producing higher amount of pods, increased seed size and longer pod.
\end{abstract}

Keywords: Growth and Yield, Mungbean, Puddling, Flooding, Saturated Soil

\section{Introduction}

Over the recent decades, the development of new mungbean varieties has contributed to a 35 percent increase in production in Asia [1]. The crop has already been transformed from a marginal to major crop for its additional benefits like enhancing soil fertility, improving rural household income, expanding employment opportunities, diversifying diets and increasing nutritional security [2]. The short-growth duration variety of mungbean is well fitted in the rice-based cropping systems of Asia. The climatic condition also favours its cultivation throughout the year. However, yields of post-rice mungbean are generally low due to many abiotic stresses majoring in excess or deficit soil moisture [3, 4]. Intensive rain generally causes transient flooding in poorly drained rice soil. Puddling of rice soil also causes structure degradation and saturates quickly. As a result, plants are adversely affected due to inadequate supply of oxygen. These adverse conditions greatly impair seed germination, stand establishment and yield of post-rice mungbean, despite sufficient availability of water in the soil profile to grow a high yielding mungbean variety without irrigation [5-7]. However, the information on the response of post-rice crops to adverse soil conditions associated with puddling and excess soil moisture are inadequate.

In Bangladesh, mungbean is grown on land previously occupied by wetland rice. After harvesting rice, the soil profile remains moist for a considerable period of time. As a result, intermittent saturation of the soil and shallow water table delay land preparation. Such adverse soil condition results in sub-optimal plant population. Soil flooding or waterlogging was reported to damage mungbean plants during the early 
growth stage and cause severe yield loss [8, 9]. The existing variety of mungbean cannot withstand under (i) adverse soil physical condition created by puddling (ii) saturated condition in poorly drained soil and (iii) soil flooding caused by heavy rain. To address these problems, search for mungbean genotypes tolerant to soil flooding is being continued and some flood-tolerant genotypes have been identified [10]. Various management techniques like sowing seeds along the tilled strip made by using a single tine to disrupt the compact zone in puddled soil have been found successful in growing mungbean [11]. However, the response of mungbean to saturated soil culture was not adequately tried hitherto. In general, research on evaluating crops under all these stresses is scanty or rather fragmentary. Since the soil physical requirements for the stand establishment and the subsequent growth of upland crops are different from those for rice in rice-based cropping system, this study examined the response of mungbean genotypes to wet puddling, flooding, and saturated soil conditions with a view to alleviate these constraints and increase the yield of mungbean.

\section{Materials and Methods}

The study was conducted at the Field Research Site of Bangabandhu Sheikh Mujibur Rahman Agricultural University, Gazipur 1706, Bangladesh during March-June 2009. Three mungbean genotypes viz. VC3950-88, VC6173A and BARI Mung-5 were taken for the evaluation. Three different conditions were created in the field i.e. wet puddling, soil flooding and saturated soil culture along with control, those maintained in main plot and mungbean varieties at sub-plot in a split-plot design. Wet puddling condition was created before sowing and seeds were sown on puddled soil following furrow methods. Unit plot size was $3.0 \times 2.4 \mathrm{~m}$ with a planting configuration of $30 \times 10 \mathrm{~cm}$. Seeds of similar size were sown after treating with vitavax 200. The crop was fertilized @ $40 \mathrm{~kg}$ of N, $60 \mathrm{~kg}$ of $\mathrm{P}_{2} \mathrm{O}_{5}$ and $40 \mathrm{~kg}$ of $\mathrm{K}_{2} \mathrm{O}$ per hectare in the form of urea, triple super phosphate and muriate of potash, respectively. Saturated soil culture is a water management practice, in which soil was maintained at near-saturation for ten days starting from two weeks after emergence. Flooding was imposed at the end of three weeks after the emergence of seedlings and continued for 3 days maintaining a flooding depth of $3-5 \mathrm{~cm}$. Plant protection measures were taken and agronomic management done whenever necessary. Data on stand establishment, the rate of emergence and vigor index were recorded from an area of $1 \mathrm{~m}^{2}$ marked immediately after sowing of seeds. Emerged seedlings were counted every day to observe the daily emergence. Percent seedling emergence was calculated from the number of seedlings emerged and the number of seed sown. Vigor index $=$ number of seedling emerged $/$ number of days of first count $+\ldots \ldots+$ number of seedling emerged / number of days of last count. Growth parameters like plant height, dry matter production of plant components, leaf area, chlorophyll content (SPAD value) were recorded at 10 days interval starting from 28 days after emergence (DAE) to 58 DAE. Yield contributing characters i.e. the number of pods per plant, pod length, the number of seeds per pod, seed weight and seed yield were recorded at the final harvest. Data were analyzed by partitioning the total variance with the help of computer using MSTATC program. The treatment means computed using Least Significance Difference (LSD).

\section{Results and Discussion}

\subsection{Seedling Emergence and Vigor Index}

Irrespective of genotypes, only wet puddling showed significant reduction in field emergence and vigor index of mungbean seedlings (Table 1). Soil resistance to seedling emergence or failure of better seed-soil contact might be the reasons for such reduction. Kirby and Ringrose-Voase (2000) [12] reported that soil conditions following puddling and after harvesting of rice could be unsuitable for succeeding upland crop like mungbean. The rapid drying of soil after harvesting rice generally increased soil strength and reduced emergence of mungbean [13]. Puddled soil was found to disrupt the physical condition of seed, consequently reducing seedling emergence as well as seedling growth [14]. The study also reveals that the seeding emergence and vigor index varied significantly across the genotypes. Maximum emergence was observed in BARI Mung-5 indicating better resistance under the three adverse situations. BARI Mung-5 is a widely used cultivated variety of mungbean in Bangladesh and may have better physiological functions. The highest vigor index of this genotype also indicated that it has the better ability to emerge quickly compared to other two genotypes.

Table 1. Effects of different moisture regimes on seedling emergence and vigor index of three mungbean genotypes

\begin{tabular}{lcc}
\hline Treatments & Emergence $(\%)$ & Vigor index \\
\hline Moisture regimes: & $59.86 \mathrm{a}$ & $19.85 \mathrm{a}$ \\
Control & $45.37 \mathrm{c}$ & $14.94 \mathrm{~b}$ \\
Wet puddling & $55.74 \mathrm{a}$ & $18.81 \mathrm{a}$ \\
Soil flooding & $56.25 \mathrm{a}$ & $1958 \mathrm{a}$ \\
Saturated soil culture & & \\
Mungbean genotypes: & $67.33 \mathrm{a}$ & $23.57 \mathrm{a}$ \\
BARI mung-5 & $46.15 \mathrm{c}$ & $14.57 \mathrm{c}$ \\
VC3950-88 & $56.94 \mathrm{~b}$ & $18.48 \mathrm{~b}$ \\
VC6173A & & \\
LSD $(0.05):$ & 4.39 & 4.53 \\
Moisture regimes & 9.90 & 3.50 \\
Variety & $\mathrm{NS}$ & $\mathrm{NS}$ \\
Moisture $\times$ genotypes & 23.89 & 25.38 \\
CV (\%) & & \\
\hline
\end{tabular}

NS, non-significant; Mean values sharing the same letter in each column do not differ significantly at $\mathrm{P}<0.05$.

\subsection{Plant Height}

Plant height was quantified four times starting from 28 
DAE with 10 days interval. Saturated soil culture affected plant height the most at different observations (Figure 1a). Under wet pudding condition, plant height was also affected at 58 DAE. Kirchhof and So (2005) [15] observed that puddling increased plant height slightly during the early vegetative stage. Height growth of flooded plants was also affected, but it showed a considerable recovery and performed almost identical to that of control plants. In many cases, flooded plants have been found to increase plant height during recovery period which is thought as an adaptive mechanism [16, 17]. Plant height differed significantly in three genotypes (Figure 1b). The height growth of VC6173A was better than other two genotypes. In another study, Pervin et al. (2010) [9] observed that VC6173A showed greater reduction in plant height compared to VC3960-88.

(a)

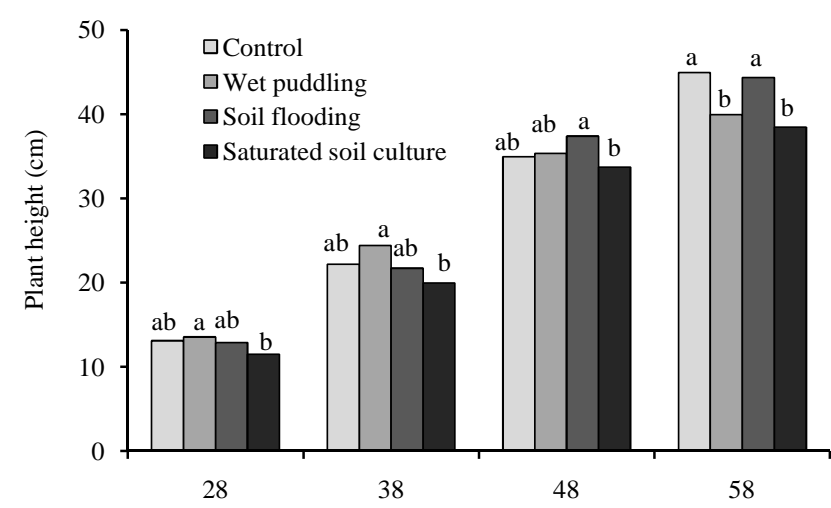

(b)

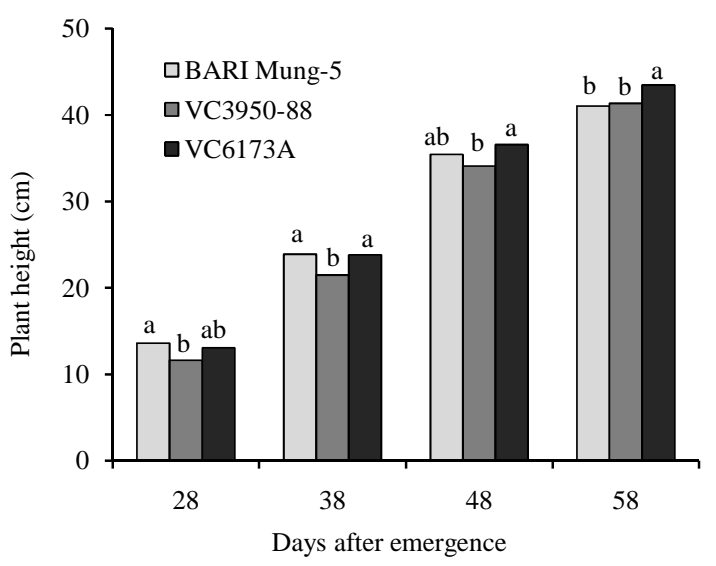

Figure 1. Plant height of three mungbean genotypes as affected by differential moisture regimes. Mean values sharing the same letter(s) are not differing significantly at $P<0.05$.

\subsection{Chlorophyll Index}

Chlorophyll content (SPAD value) of leaf was significantly affected at different stages of crop growth starting from 28 DAE (Figure 2a). The highest leaf chlorophyll content was recorded in control plants followed by plants subjected to flooding. However, chlorophyll content dramatically recovered fully in plants under all the stresses at 58 DAE. Marubodee et al. (2000) [18] reported that leaf chlorophyll content of mungbean reduced under anoxia, although a good deal of recovery in leaf chlorophyll content of waterlogged mungbean plants have been observed in many studies $[9,19]$. Genotypic differences in chlorophyll content were not notable in this study, although significant difference existed only at 38 DAE (Figure 2b).

(a)

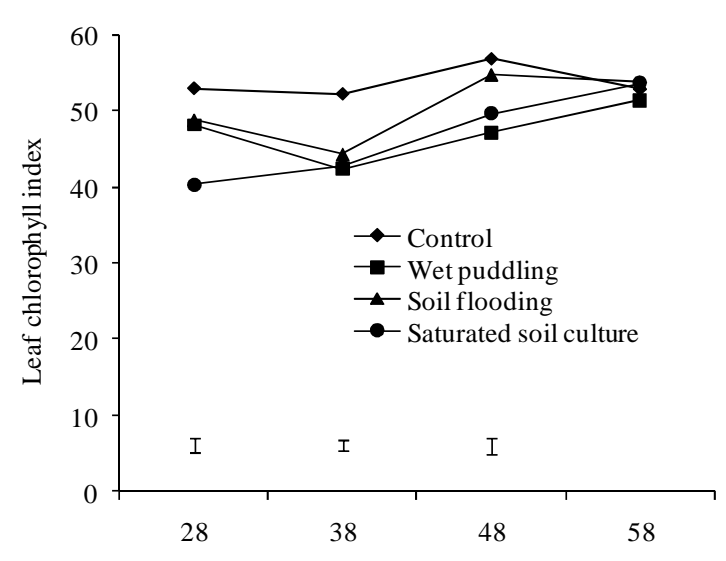

(b)

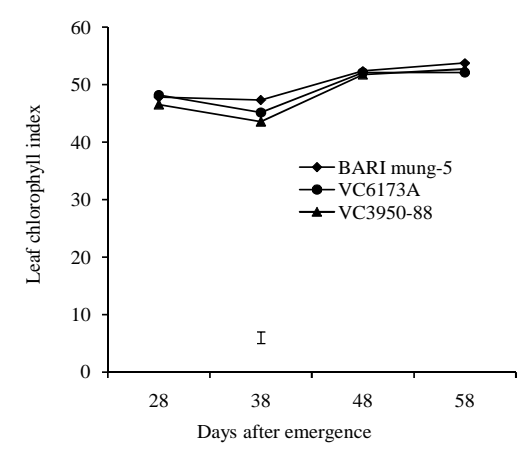

Figure 2. Leaf chlorophyll index (SPAD value) of three mungbean genotypes as affected by differential moisture regimes. Bar indicates LSD at 0.05.

\subsection{Root and Shoot Dry Matter}

The shoot and root dry weights (DW) were significantly affected by wet puddling, flooding and saturated soil culture (Table 2). Similar observations have also been reported in several crop plants [20, 21]. Among the stresses, puddled soil impaired root growth the most. Puddling resulted in reduced root growth particularly at the early stages of crop growth. Subsequent growth during the latter part of the growing season was therefore restricted due to roots being less able to tap subsoil water reserves [22]. Root growth was also affected by soil flooding, but recovered almost wholly at 58 DAE. In 
general, roots of mungbean plants damaged immediately after flooding, but plants used to produce adventitious roots within 48 hours of flooding [23]; after the death of original roots, plants were found to acclimatize with flooding situation by accelerating new adventitious roots [24, 10, 25]. Like root DW, shoot DW was also affected due to stresses. The adverse effect of saturated soil culture on shoot DW was more pronounced over time, though a faster shoot growth was observed at the maturity stage. However, mungbean plants showed an early reduction in shoot dry matter due to flooding, but had considerable recovery after the removal of flooding. The decrease in dry matter accumulation due to flooding and its recovery after the termination of flooding is a common phenomenon in mungbean $[26,27]$.

Table 2. Effects of different moisture regimes on shoot and root dry weight of mungbean genotypes

\begin{tabular}{|c|c|c|c|c|}
\hline \multirow{2}{*}{ Treatments } & \multicolumn{4}{|c|}{ Days after emergence } \\
\hline & 28 & 38 & 48 & 58 \\
\hline \multicolumn{5}{|c|}{ Shoot dry weight $\left(g\right.$ plant $\left.^{-1}\right)$} \\
\hline Control & $2.38 \mathrm{a}$ & $3.95 \mathrm{a}$ & $9.49 \mathrm{a}$ & $12.06 \mathrm{a}$ \\
\hline Wet puddling & $1.26 \mathrm{~b}$ & $2.65 \mathrm{~b}$ & $8.07 \mathrm{~b}$ & $9.49 \mathrm{~b}$ \\
\hline Soil flooding & $1.70 \mathrm{~b}$ & $2.10 \mathrm{~b}$ & $7.17 \mathrm{~b}$ & $11.40 \mathrm{a}$ \\
\hline Saturated soil culture & $0.72 \mathrm{c}$ & $1.80 \mathrm{c}$ & $5.62 \mathrm{c}$ & $10.05 \mathrm{ab}$ \\
\hline \multicolumn{5}{|c|}{ Root dry weight (g plant $\left.{ }^{-1}\right)$} \\
\hline Control & $0.25 \mathrm{a}$ & $0.39 \mathrm{a}$ & $0.62 \mathrm{a}$ & $0.80 \mathrm{a}$ \\
\hline Wet puddling & $0.13 \mathrm{c}$ & $0.28 \mathrm{c}$ & $0.45 \mathrm{c}$ & $0.53 \mathrm{c}$ \\
\hline Soil flooding & $0.17 \mathrm{~b}$ & $0.33 \mathrm{~b}$ & $0.56 \mathrm{~b}$ & $0.80 \mathrm{a}$ \\
\hline Saturated soil culture & $0.18 \mathrm{~b}$ & $0.29 \mathrm{c}$ & $0.51 \mathrm{~b}$ & $0.65 \mathrm{~b}$ \\
\hline
\end{tabular}

Mean values sharing the same letter in each column do not differ significantly at $\mathrm{P}<0.05$.

\subsection{Root Nodules}

The saturated soil culture produced the abundant root nodules which was significantly higher than that produced in control plants (Figure 3). Several studies also suggest that saturated soil culture produced a large amount of root nodules in soybean that remained throughout the growing period, and nitrogen fixation activity acted in response to that pattern of nodulation [28-30]. Soil flooding reduced the formation of root nodules up to 38 DAE, thereafter it noticeably increased at 48 DAE. Flooding generally reduced the number of root nodules, but the magnitude of reduction varied with the growth stages encountering flooding. However, the actual number and volume of nodules have been found to increase depending on the capacity of the plants to produce nodules [31]. In contrast, wet puddling largely impaired nodulation in mungbean and it showed a large gap with that produced in control plants. Puddled soils are compacted and attained increased soil bulk density for which the weight and size of nodules in soybean have been found to reduce significantly [32].

\subsection{Yield Attributes and Seed Yield}

Yield attributes and seed yield of mungbean as affected by wet puddling, flooding and saturated soil culture are illustrated in Table 3. The number of pods per plants, seed weight and seed yield were significantly affected due to stresses. Soil puddling and saturated soil culture significantly reduced the number of pods per plant, but flooding adversely affected the seed weight. However, Wein et al. (1979) [33] observed that the number of pods in cowpea and soybean reduced due to flooding. The reduction in seed yield was significant due to stresses, however such reduction was minimal after removal of stresses presumably for rapid recovery of root system under flooding and numerous nodule production under saturated soil culture. Among the stresses, puddling gave the lowest seed yield which was $64 \%$ of that produced in control plants. Puddling induced several physiological disturbances, including reduction in growth, dry matter, chlorophyll index and pod formation that resulted in low yield similar to that in other beans [34, 24, 35]. The genotypic differences in seed yield were highly remarkable in the study. The genotype VC6173A gave significantly higher yield over BARI Mung-5 and VC3950-88. Producing greater amount of pods with greater seed size, and even longer pod length contributed greatly to produce the highest seed yield in VC6173A.

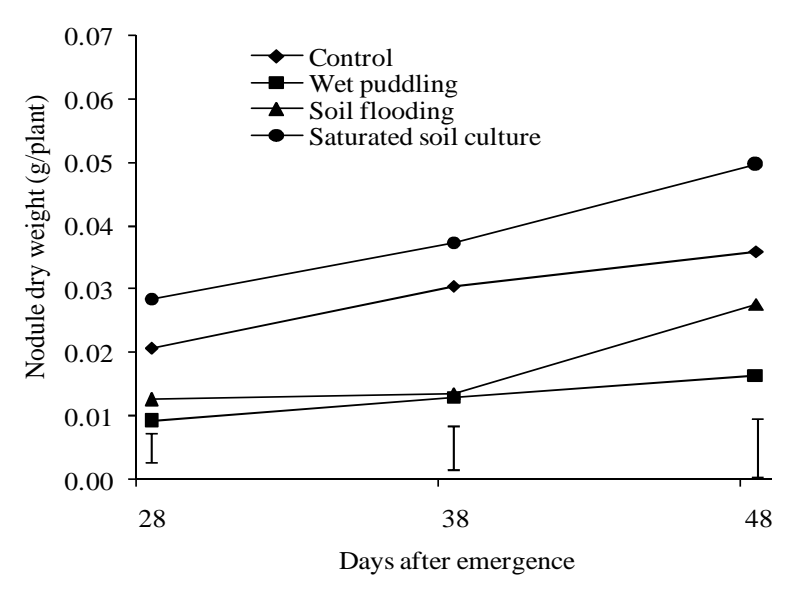

Figure 3. Effects of different moisture regimes on nodule dry weight of mungbean genotypes. Bar indicates LSD at 0.05

\section{Conclusion}

Mungbean has tremendous scope of horizontal expansion because of its wide range of adaptability. In rice-based cropping system, its growing conditions become unfavorable due to puddling of soil and associated problems caused by excess soil moisture. The response of mungbean genotypes varied significantly depending on the types of such varying stresses. This study reveals that soil puddling for rice affected much on the production of post-rice mungbean due to poor stand establishment. The plant recovery from flooding injury was better for which yield was not seriously affected. Under saturated soil culture, the numerous nodules formation contributed to give better yield finally. The effects of genotypic differences under three growing conditions were also evident. Therefore, attempts 
should be taken to improve the production system of mungbean through genetic and agronomic management for the improvement and sustainability of growing mungbean in future.

Table 3. Effects of different moisture regimes on yield attributes and seed yield of three mungbean genotypes

\begin{tabular}{|c|c|c|c|c|c|}
\hline Treatments & $\begin{array}{l}\text { No. of } \\
\text { pods } \\
\text { plant }^{-1}\end{array}$ & $\begin{array}{c}\text { Pod } \\
\text { length } \\
\text { (cm) }\end{array}$ & $\begin{array}{l}\text { No. of } \\
\text { seeds } \\
\text { pod }^{-1} \\
\end{array}$ & $\begin{array}{c}\text { 100-seed } \\
\text { weight } \\
(\mathrm{g})\end{array}$ & $\begin{array}{c}\text { Seed } \\
\text { yield } \\
\text { plant }^{-1} \\
\end{array}$ \\
\hline \multicolumn{6}{|l|}{$\begin{array}{l}\text { Moisture } \\
\text { regimes: }\end{array}$} \\
\hline Control & $34.05 \mathrm{a}$ & 8.38 & 9.31 & $5.80 \mathrm{a}$ & $14.46 \mathrm{a}$ \\
\hline Wet puddling & $25.76 \mathrm{~b}$ & 8.29 & 9.67 & $5.45 \mathrm{a}$ & $9.27 \mathrm{c}$ \\
\hline Soil flooding & $30.83 \mathrm{a}$ & 8.24 & 10.10 & $4.69 \mathrm{~b}$ & $11.77 \mathrm{~b}$ \\
\hline $\begin{array}{l}\text { Saturated soil } \\
\text { culture } \\
\text { Mungbean } \\
\text { genotypes: }\end{array}$ & $25.82 \mathrm{~b}$ & 8.61 & 9.31 & $5.41 \mathrm{ab}$ & $10.19 \mathrm{bc}$ \\
\hline BARI Mung-5 & $27.21 \mathrm{~b}$ & $8.43 \mathrm{c}$ & 9.88 & $5.02 \mathrm{~b}$ & $10.51 \mathrm{~b}$ \\
\hline VC3950-88 & $28.37 \mathrm{ab}$ & $7.86 \mathrm{~b}$ & 9.39 & $5.13 \mathrm{~b}$ & $10.92 \mathrm{~b}$ \\
\hline VC6173A & $31.77 \mathrm{a}$ & $8.84 \mathrm{a}$ & 9.52 & $5.86 \mathrm{a}$ & $12.84 \mathrm{a}$ \\
\hline \multicolumn{6}{|l|}{$\operatorname{LSD}_{(0.05)}$} \\
\hline $\begin{array}{l}\text { Moisture } \\
\text { regimes }\end{array}$ & 3.78 & NS & NS & 0.74 & 1.74 \\
\hline Variety & 3.41 & 0.35 & NS & 0.59 & 1.44 \\
\hline $\begin{array}{l}\text { Moisture } \times \\
\text { genotypes }\end{array}$ & NS & NS & NS & NS & NS \\
\hline $\mathrm{CV}(\%)$ & 16.05 & 5.67 & 6.25 & 15.23 & 17.24 \\
\hline
\end{tabular}

NS, non-significant; Mean values sharing the same letter in each column do not differ significantly at $\mathrm{P}<0.05$.

\section{Acknowledgements}

Authors highly acknowledge (i) the University Grant Commission (UGC) of Bangladesh for providing financial assistance and (ii) the Research Management Committee (RMC) of Bangabandhu Sheikh Mujibur Rahman Agricultural University (BSMRAU) for administrative support to conduct the research.

\section{References}

[1] K. Weinberger. Impact Analysis of Mungbean Research in South and Southeast Asia. Final Report of GTZ Project. The World Vegetable Center (AVRDC), Shanhua, Taiwan, 2003.

[2] S. Shanmugasundaram, J. D. H. Keatinge, and J. Hughes. Counting on Beans: Mungbean Improvement in Asia. In: D.J. Spielman and R. Pandya-Lorch (ed.) Millions fed: Proven Successes in Agricultural Development. IFPRI: Washington DC, 2009.

[3] A. Ramakrishna, C. L. L. Gowda, and C. Johansen. Management factors affecting legumes production in the Indo-Gangetic Plain. In: Legumes in rice and wheat cropping systems of the Indo-Gangetic Plain-constraints and opportunities. International Crops Research Institute for the Semi-Arid Tropics, Patancheru, Andhra Pradesh, India. pp.
156-165, 2000.

[4] D. P. Singh, and B. B. Singh. Breeding for tolerance to abiotic stresses in mungbean. J. food legumes, vol. 24, pp. 83-90, 2011.

[5] T. C. Helms, B. J. Werk, B. D. Nelson, and E. Deckard. Soybean tolerance to water-saturated soil and role of resistance to Phytophthora sojae. Crop Sci., vol, 47, pp. 2295-2302, 2007.

[6] H. B. So, and A. J. Ringrose-Voase. Management of clay soils for rainfed lowland rice-based cropping systems: an overview. Soil Tillage Res., vol. 56, pp. 3-14, 2000.

[7] G. Kirchhof, S. Priyono, W. H. Utomo, T. Adisarwanto, E. V. Dacanay, and H. B. So. The effect of soil puddling on the soil physical properties and the growth of rice and post-rice crops. Soil Tillage Res., vol. 56, pp. 37-50, 2000.

[8] Islam, M. R., A. Hamid, M. A. Karim, M. M. Haque, Q. A. Khaliq, J. U. Ahmed. Gas exchanges and yield responses of mungbean (Vigna radiata $\mathrm{L}$. Wilczek) genotypes differing in flooding tolerance. Acta Physiol. Plant., vol. 30, pp. 697-707, 2008.

[9] T. Pervin, M. R. Islam, A. Hamid, M. M. Haque, and J. U. Ahmed. Soil flooding tolerance in mungbean under field condition. Bangladesh Agron. J., vol. 13, pp. 41-50, 2010.

[10] M. R. Islam, A. Hamid, Q. A. Khaliq, J. U. Ahmed, M. M. Haque, and M. A. Karim. Genetic variability in flooding tolerance of mungbean (Vigna radiata L. Wilczek) genotypes. Euphytica, vol.156, pp. 247-255, 2007.

[11] S. G. Maghari, and T. Woodhead. Tillage in a rainfed lowland cropping sequence. Presented to a Saturday Seminar at IRRI, October 1984. Los Banos, Philippines: International Rice Research Institute, 1984.

[12] J. M. Kirby, and A.J. Ringrose-Voase. Drying of some Philippine and Indonesian puddled rice soils following surface drainage: Numerical analysis using a swelling soil flow model. Soil Tillage. Res., vol. 57, pp. 13-30, 2000.

[13] S. M. F. Cook, S. C. Gupta, T. Woodhead, and W. E. Larson. Soil physical constraints to establishment of mungbeans (Vigna radiata L. Wilczek) in paddy rice (Oryza sativa L.) soils. Soil Tillage. Res., vol. 33, pp. 47-64, 1995.

[14] P. B. S. Bhadoria. Characterization of physical condition of puddled and nonpuddled soil. J. Agronomy Crop Sci., vol. 159, pp. 216-218, 1987.

[15] G. Kirchhof, and H. B. So. Rice growth and post-rice mungbean in relation to two puddling intensities under glasshouse conditions. Australian J. Soil Res., vol. 43, pp. 617-622, 2005.

[16] P. Insausti, A. A. Grimoldi, E. J. Chaneton, and V. Vasellati. Flooding induces a suite of adaptive plastic responses in the grass Paspalum dilatatum. New Phytol., vol. 152, pp. 291-299, 2001.

[17] G. G. Striker, P. Insausti, A. A. Grimoldi, E. L. Ploschuk, and V. Vasellati. Physiological and anatomical basis of differential tolerance to soil flooding of Lotus corniculatus L. and Lotus glaber Mill. Plant Soil, vol. 276, pp. 301-311, 2005.

[18] R. Marubodee, S. Chakhatrakan and H. Ehara,. Comparison of growth of Azuki, cowpea and mungbean with aeration and non-aeration under hydroponic technique. Thai J. Sci. and Tech., pp. 61-68, 2000. 
[19] H. H. Oo, T. Araki, and F. Kubota. Effects of drought and flooding stresses on growth and photosynthetic activity of mungbean, Vigna radiata (L.) Wilczek cultivars. J. Fac. Agric. Kyushu Univ., vol. 50, pp. 533-542, 2005.

[20] K. Shi, W. Hu, D. Dong, Y. Zhou, and J. Yu. Low $\mathrm{O}_{2}$ supply is involved in the poor growth in root-restricted plants of tomato (Lycopersicon esculentum Mill.). Environ Exp. Bot., vol. 61, pp. 181-189, 2007.

[21] T. Bai, C. Li, F. Ma, F. Feng, and H. Shu. Responses of growth and antioxidant system to root-zone hypoxia stress in two Malus species. Plant Soil, vol. 327, pp. 95-105, 2010.

[22] S. T. Willatt, and R.Trangono. Puddling, its effect on soil physical properties. In: Coughan, K.J., Truong, P.N. (ed.), Effect of Management Practices on Soil Physical Properties, Queensland Department of Primary Industries Conference and Workshop Series QC87006, Brisbane, Australia, 1987.

[23] M. R. Islam. Eco-physiology of Soil Flooding Tolerance in Mungbean. Ph.D. Diss., Dept. Agronomy., Bangabandhu Sheikh Mujibur Rahman Agricultural University, Gazipur-1706, Bangladesh, 2003.

[24] E. Pociecha, J. Koscielniak, and W. Filek. Effect of root flooding and stage of development on the growth and photosynthesis of field bean (Vicia faba L. minor). Acta Physiol. Plant., vol. 30, pp. 529-535, 2008.

[25] H. Greenway, W. Armstrong, and T. D. Colmer. Conditions leading to high $\mathrm{CO}_{2}(>5 \mathrm{kPa})$ in waterlogged-flooded soils and possible effects on root growth and metabolism. Ann. Bot., vol. 98, pp. 9-32, 2006.

[26] M. R. Islam., A. Hamid, Q. A. Khaliq, J. U. Ahmed, and M. M. Haque. Response of mungbean to soil flooding at vegetative stage I. Root and shoot growth. Bangladesh Agron. J., vol. 11, pp. 1-9, 2005.

[27] S. Ahmed, E. Nawata, and T. Sakuratani. Effects of waterlogging at vegetative and reproductive growth stages on photosynthesis, leaf water potential and yield of mungbean. Plant Prod Sci., vol. 5, pp. 117-123, 2002.

[28] W. Guafa, M. B. Peoples, D. B. Herridge, and B. Rerkasem. Nitrogen fixation, growth and yield of soybean grown under saturated soil culture and conventional irrigation. Field Crop Res., vol. 32, pp. 257-268,1993.

[29] R. J. Troedson, R. J. Lawn, D. E. Byth, and G. L. Wilson. Response of field-grown soybean to saturated soil culture. I. Patterns of biomass and nitrogen accumulation. Field Crops Res., vol. 21, pp. 171-187, 1989.

[30] K. Nathanson, R. J. Lawn, P. L. M. De Jabrun, D. E. Byth. Growth, nodulation and nitrogen accumulation by soybean in saturated soil culture. Field Crops Res., vol. 8, pp. 73-92, 1984.

[31] G. Jung, T. Matsunami, Y. Oki, and M. Kokubun. Effects of waterlogging on nitrogen fixation and photosynthesis in supernodulating soybean cultivar Kanto 100. Plant Prod. Sci., vol. 11, pp. 291-297, 2008.

[32] D. Paredes, M. Roba, J. P. D'Amico, A. Romito, and O. Tesouro. Effect of soil compaction on the nodulation and yields on soybean crop. CIGR-International Conference of Agricultural Engineering, XXXVII Congresso Brasileiro de Engenharia Agricola, Brazil, 2008.

[33] C. Wein, R. Lal, and E. L. Pulver. Effects of transient flooding on growth and yield of some tropical crops. pp. 234-245. In: Lal R., Greenland D. J. (ed) Soil Physical Properties and Crop Production in the Tropics. Wiley, Chichester, 1979.

[34] G. Celik, and E. Turhan. Genotypic variation in growth and physiological responses of common bean (Phaseolus vulgaris L.) seedlings to flooding. Afr. J. Biotechnol., vol. 10, pp.7372-7380, 2011.

[35] Z. Solaiman, T.D. Colmer, S. P. Loss, B. D. Thomson, and K. H. M. Siddique. Growth responses of cool-season grain legumes to transient waterlogging. Aust J. Agric. Res., vol. 58, pp. 406-412, 2007. 